\title{
Vacuum packed particles as flexible endoscope guides with controllable rigidity
}

\author{
Arjo J. Loeve • Oscar S. van de Ven • Johan G. Vogel • \\ Paul Breedveld · Jenny Dankelman
}

Received: 28 May 2009 / Published online: 24 June 2010

(c) The Author(s) 2010. This article is published with open access at Springerlink.com

\begin{abstract}
In order to fully benefit from the functionalities of flexible endoscopes in surgery a simple shaft-guide that can be used to support the flexible endoscope shaft is required. Such a shaft-guide must be flexible during insertion into the human body and rigidified when properly positioned to support the flexible endoscope shaft. A shaft-guide called 'Vacu-SL' was designed, consisting of a foil tube, filled with particles, that is rigidified by creating a vacuum in its tube. It is expected that the bending stiffness of a loaded, rigidified Vacu-SL shaft-guide is significantly influenced by the shape, hardness and size of the filler particles used. The goal of this study was to find the relations between the filler particles' size, shape and hardness and a rigidified Vacu-SL shaft-guide's bending stiffness. Vacu-SL test models were made using polystyrene, acrylic glass, glass, steel, and corundum particles as spheres, pebbles and granulate, with average diameters between $0.16-1.7 \mathrm{~mm}$. These test models were rigidified and then loaded in a tensile tester. The forces needed for 5 and $10 \mathrm{~mm}$ deflections of the rigidified test models were measured. The results show that particle size, shape and hardness all influence a rigidified Vacu-SL shaft-guide's bending stiffness. Size and hardness showed an optimum and granules performed better than spheres. Although the maximally measured bending stiffness might be insufficient to enable proper guidance of flexible endoscope shafts, the results suggest several ways to successfully improve the Vacu-SL shaft-guide.
\end{abstract}

\footnotetext{
A. J. Loeve $(\bowtie) \cdot$ O. S. van de Ven · J. G. Vogel · P. Breedveld J. Dankelman

Department BioMechanical Engineering, Faculty $3 \mathrm{mE}$, Delft University of Technology, Mekelweg 2, 2628 CD, Delft, the Netherlands e-mail: A.J.Loeve@TUDelft.nl

URL: http://www.misit.nl
}

Keywords Size $\cdot$ Shape $\cdot$ Hardness $\cdot$ Vacuum $\cdot$ Shaft-guide . Endoscopy

\section{Introduction}

In the medical field, flexible endoscopes [1] are used for many diagnostic and therapeutic applications in and around the digestive tract. Flexible endoscopes are long, flexible insertion tubes that contain a camera, light source and working channels for small instruments. In colonoscopy (endoscopy of the large bowel) and Natural Orifice Translumenal Endoscopic Surgery (NOTES, abdominal surgery through natural body orifices), the flexibility of these instruments is not only an absolute necessity, but also the major cause of several difficulties [2-12].

An example of a situation in NOTES wherein the flexibility of an endoscope shaft causes difficulties is depicted in Fig. 1: A flexible endoscope is inserted through a patient's mouth and esophagus and then through a hole in the stomach wall to reach an organ that needs surgery. In order to enable this insertion, the endoscope shaft must be flexible. After inserting the flexible endoscope, a grasper is introduced through a working channel in the flexible endoscope. This grasper is used to manipulate a piece of tissue of the organ that is to be treated. When the grasper is used to pull the piece of tissue, the flexible endoscope bends because it is not stiff enough to fully resist the forces and provide a stable working platform.

There is a conflict between the desire to have a stiff endoscope shaft, providing a stable working platform during tissue manipulations, and the necessity to have a flexible endoscope shaft, enabling insertion through tortuous body cavities. An attractive solution would be to have an endoscope shaft with a rigidity that can be controlled, or with an over-tube with a 


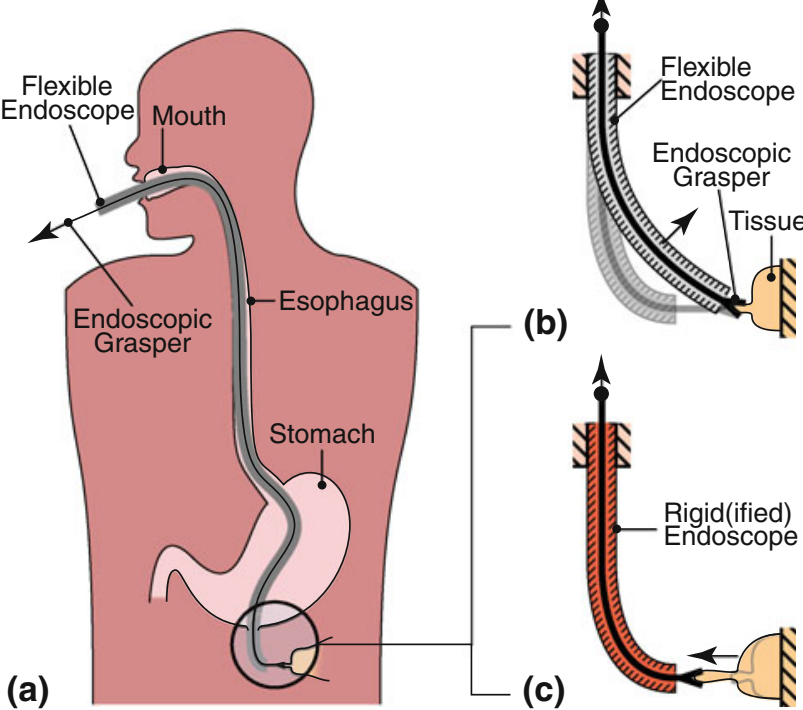

Fig. 1 Endoscope flexibility problem in NOTES through the stomach wall. a A flexible endoscope is inserted into the colon through the patient's mouth and esophagus. An incision is made in the stomach wall to advance towards tissue that is to be treated. A grasper, inserted through the endoscope, is used to manipulate the tissue. $\mathbf{b}$ In practice: When pulling the grasper in order to pull tissue towards the endoscope, the flexible endoscope shaft moves towards the tissue instead. $\mathbf{c}$ Desired situation: The endoscope shaft is rigid and provides a stable working platform, enabling tissue manipulations without undesired movements of the endoscope

rigidity that can be controlled, so that it can be adapted to each phase, insertion and manipulation, of the intervention.

A relatively simple way to control the rigidity of a flexible shaft is to use vacuum to tightly pack a volume of small particles. Such mechanisms have been proposed in patents for penile prostheses, foldable structures and over-tubes [1316]. However, such vacuum based shape-lock mechanisms (from now on addressed to as Vacu-SL mechanism) have, to our best knowledge, neither been evaluated for flexible endoscope shafts, nor in an over-tube. In order to investigate the suitability of a Vacu-SL mechanism as a rigidity control mechanism for flexible endoscope shafts, we constructed and tested several physical test models.

\subsection{Physical test models}

Each test model is a $15 \mathrm{~cm}$ long Vacu-SL shaft with a diameter of $17.8 \mathrm{~mm}$ (Figs. 2 and 3). A Vacu-SL shaft exists of a thin foil tube ( $12 \mathrm{~cm}$ effective length, $17.8 \mathrm{~mm}$ diameter, artificial bowel for sausages, obtained from "Nederlandse Darmenhandel N.D.H. B.V.", Almere, The Netherlands) closed at its distal end with a tip part. The foil tube is filled with small filler particles and closed at its proximal end with a hose connector. The inner hole in the hose connector is covered with a cotton cloth membrane to prevent filler particles from entering
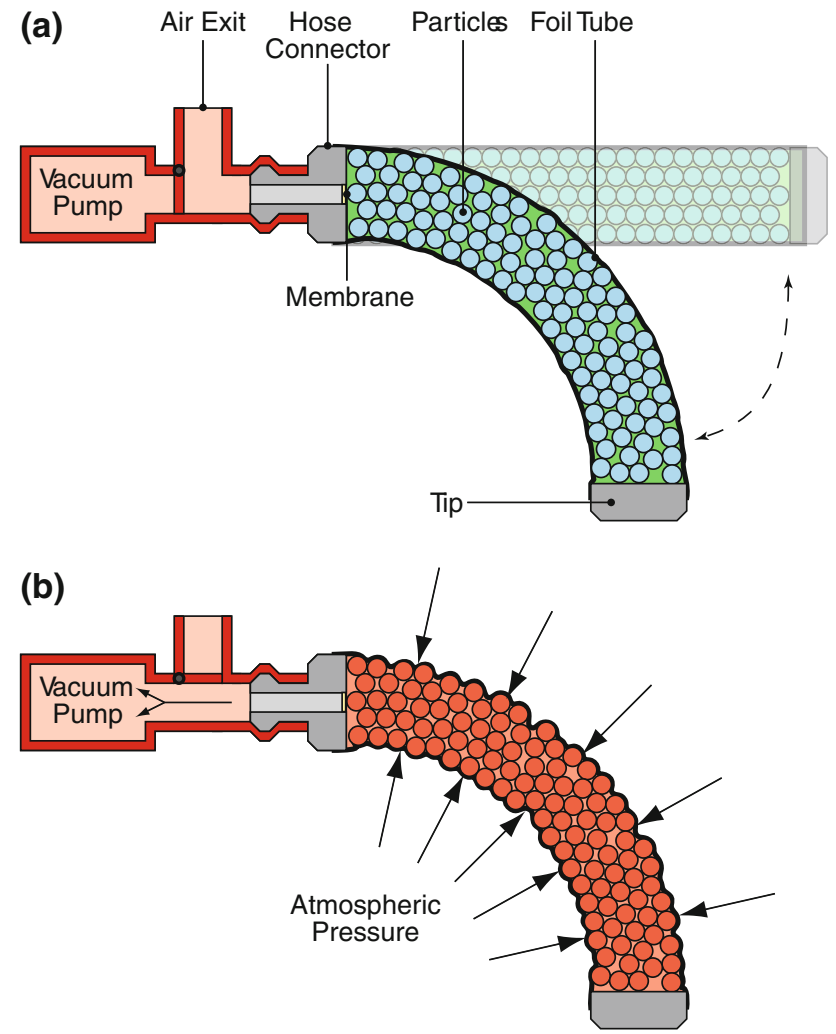

Fig. 2 The Vacu-SL mechanism. a Compliant: The filler particles are relatively unconstrained in the foil tube. b Rigidified: By creating vacuum in the foil tube, foil and particles are pressed together. Moving of the particles is restrained. (Adapted from [16])

the connector channel. The hose connector is connected to a vacuum pump. When the vacuum pump is switched off, the Vacu-SL shaft is in its compliant state and can easily bend because the particles have space to move inside the foil tube when the compliant Vacu-SL shaft is being bent. When the vacuum pump is switched on, the Vacu-SL shaft is in its rigidified state; due to the vacuum inside the tube the volume of particles is compressed by the atmospheric pressure, which inhibits movements of the particles. The atmospheric pressure acts as a locking pressure to keep the particles in place.

In order to be suitable for rigidity control for flexible endoscope shafts, a Vacu-SL shaft should have a very low bending stiffness in its compliant state, so that it can easily be advanced through the tortuous human gastro-intestinal track. A Vacu-SL shaft should have a high bending stiffness in its rigidified state, so that it can support the flexible endoscope and provide sufficient support for flexible instruments that are used through it during interventions.

Pilot tests were conducted during manufacturing of the first test models, in the same manner as the tests described later in this article. These pilot tests indicated that the foil tube material has minor influence on the bending stiffness 


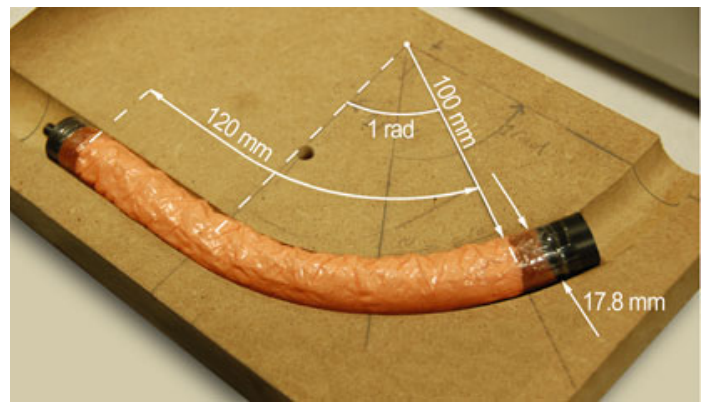

Fig. 3 Dimensions of the Vacu-SL test model and the mould that is used to rigidify the test models in a standardized shape for the measurements

of a rigidified Vacu-SL shaft when using foils ranging from relatively thick artificial bowel to very thin and elastic cellophane. This is especially true when deformations of the rigidified Vacu-SL shaft are small, which should be the case if the instrument functions properly, and the foil is wrinkled around the filler particles. Therefore a foil tube material was chosen that was readily available and easily processed. The bending stiffness of the Vacu-SL shafts in their compliant states was negligible compared to their rigidified states for all types of filler particles. At constant vacuum pressure, the bending stiffness of a rigidified Vacu-SL shaft depends primarily on the type of particles that is used to fill the foil tube.

\subsection{Goal}

The goal of this research was to explore the relation between the bending stiffness of a rigidified Vacu-SL shaft and the type of filler particles used in it, and to estimate whether the Vacu-SL mechanism is suitable for application in flexible endoscopes. When known, this relation can be used to choose the right filler particles for a Vacu-SL shaft that is to be used in an endoscope with rigidity control. Only homogeneous fillings of single types of relatively hard filler particles were investigated. Hypotheses were formulated based on our observations in the pilot tests, theory, and results obtained by other researchers.

\subsection{Theory and literature}

For simplicity, the filler particles are initially regarded as close packed spheres. In order for such a volume of particles to deform, the particles of that volume must either move with respect to one another or deform. When such a volume deforms it will start dilating due to the nature of its packing [17]. The Vacu-SL mechanism is based on counteracting the deformation and dilation of a volume of filler particles. Two different particle interaction mechanisms are known to be underlying the deformations of the filler volume

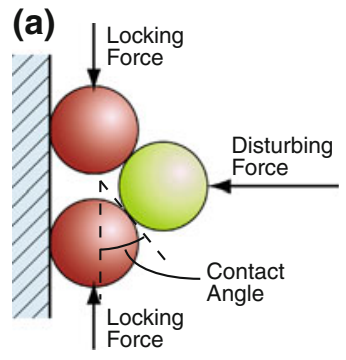

(b)

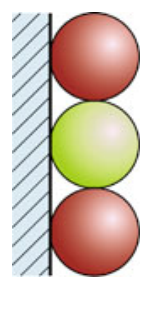

Fig. 4 Particle intrusion. a The locking force, which is caused by the pressure difference between the inside and outside of the foil tube in a rigidified Vacu-SL shaft, acts to keep the particles in place. When the rigidified Vacu-SL shaft is bended by an external force, this causes a disturbing force to act on the filler particles. Deformation of the VacuSL shaft due to particle intrusion occurs due to particles being pushed into another layer of particles by the disturbing force. b Filler particles after a particle intruded a neighboring layer

as a whole (total deformation): particle rearrangements and particle deformation.

- Particle rearrangement occurs when particles change position or orientation within a pack of particles. When considering the rearrangments on a particle level, this can be because a particle is pushed in between the particles of a neighboring layer of particles (particle intrusion) or pushed over particles of an underlying layer (particle hopping).

Particle intrusion (Fig. 4) can only occur if the contact angle is large enough, if a sufficiently large disturbing force is acting on the intruding particle and if friction between the particles is sufficiently low or if the particle can roll. The critical contact angle, below which particle intrusion by sliding cannot occur, equals the arctangent of the coefficient of friction between the particles (assuming Coulomb friction). If the particles are 'edgy' (particles that are irregularly shaped or have blunt edges and few, but relatively large, straight surfaces) there are many small contact angles, like in a brick wall, restraining particle intrusion.

For particle hopping to occur (Fig. 5), a sufficiently large disturbing force must be acting on the upper particle in order to push it over an underlying particle. The disturbing force must be directed sufficiently horizontal or upwards, since otherwise, it will make the particle intrude the underlying layer. Friction should be low to allow sliding of the top particle over the bottom particles or the top particle should be able to roll over the bottom particles. In both cases the slope angle (Fig. 5) must be sufficiently small. Particle hopping resembles shearing in granular media, especially when multiple particles or an entire layer of particles moves at once [18].

Olson et al. performed experiments on avalanches in piles of particles [19]. They showed that the stability of a pile 

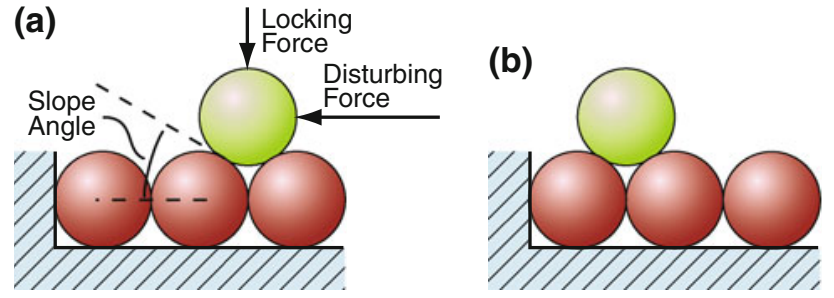

Fig. 5 Particle hopping. a Filler particles before being moved by a disturbing force that is caused by loading the Vacu-SL shaft. The locking force, which is caused by the pressure difference between the inside and outside of the foil tube, acts to keep the particles in place. b Filler particles after a particle hopped over underlying particles

of particles is less for round particles than for hexagonal or parallelogram shaped particles. It requires more force to make particles hop over each other for hexagonal or parallelogram shaped particles than for round particles. Other researches showed that particle shape is an important factor in packing stability [20-23] and that spheres and ellipsoids have similar rolling abilities [24]. Vacu-SL shafts filled with edgy particles are therefore expected to have a higher bending stiffness than those filled with spheres or ellipsoids.

The gravitational force on the particles scales with the third power of the particle diameter. However, even for $1 \mathrm{~mm}$ diameter steel particles, the gravitational force is about a thousand times smaller than the locking force acting on a particle. This locking force is the resultant of the vacuum pressure acting on the particle from one side and is directly related to its cross sectional area, the squared particle diameter. The disturbing force acting on a particle also relates to the squared particle diameter since it is the resultant of a pressure too; the bending stresses. Therefore, it is expected that there is no direct influence of particle scaling on the balance between the locking and disturbing force magnitudes.

There is, however, another effect that occurs due to scaling of the filler particles. The number of layers of particles in a Vacu-SL shaft depends on the particle size. Depending on the diameters of the shaft and the used particles, the number of layers can become relatively small. Both the stability of granular packings as the probability distributions of forces are known to be sensitive to the number of layers up to a certain limit [25-27]. These effects suggest that particle size will influence the Vacu-SL shaft stiffness.

- Particle deformation can both promote and inhibit the total deformation (Fig. 6). Due to compression of particles by the disturbing force, the stack height is reduced, which causes deformation of the Vacu-SL shaft. This was illustrated by the simulations of Kadau et al. [28], showing that softer particles allow for more deformation with-

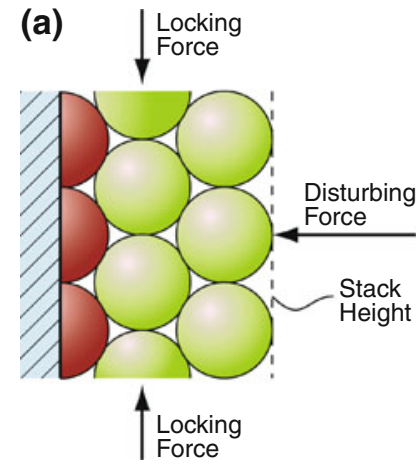

(b)

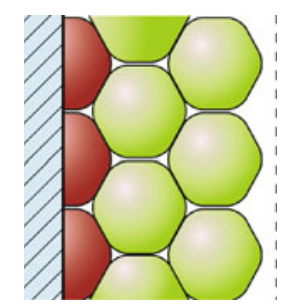

Fig. 6 Particle deformation. a Filler particles before moving and deforming due to the disturbing force that is created due to loading the Vacu-SL shaft. The locking force, which is caused by the pressure difference between the inside and outside of the foil tube, acts to keep the particles in place. b Due to deformation of the particles, the new stacking height is smaller. However, the particle shape also changed. The new particle shape allows a more stable configuration, limiting particle intrusion and hopping

out dilation. This implies that this part of the Vacu-SL deformation will not be countered by the locking pressure.

However, the very same compression of the particles could simultaneously cause the particles to change from circular (in 2D) to shapes that are more resembling hexagons (or other polygons, depending on packing type and particles' shapes). As discussed above, a pile of edgy particles is more stable than a pile of spheres [19]. Therefore, slight particle deformation might increase the bending stiffness of the Vacu-SL haft.

The level of particle deformation depends on the stiffness or hardness of the particles. A lower hardness will result in more particle deformation. However, whether a lower hardness of the particles results in a higher or in a lower bending stiffness of the Vacu-SL shaft, is yet unclear. This depends on what effect dominates: column height reduction or limitation of particle rearrangement due to particle shape change

\subsection{Hypotheses}

Three filler particle properties were investigated for their effect on the bending stiffness of a Vacu-SL shaft: size, shape, and hardness. The null hypotheses regarding these properties are;

- There is no effect of the filler particle size on the bending stiffness of a Vacu-SL shaft. $\left(\boldsymbol{H}_{0, \mathrm{~s}}\right)$

- There is no effect of the filler particle shape on the bending stiffness of a Vacu-SL shaft. $\left(\boldsymbol{H}_{0, \mathrm{v}}\right)$ 


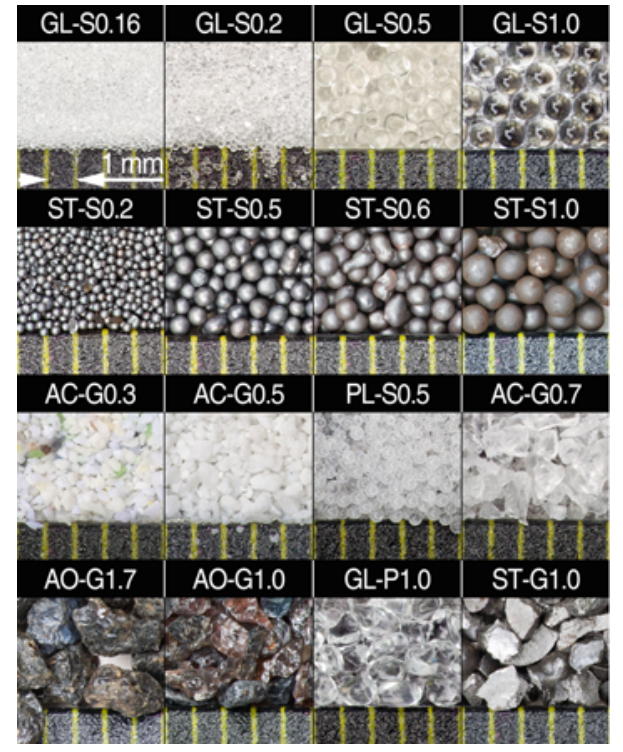

Fig. 7 Macro photographs of the tested filler particles. Properties of the filler particles are listed in Table 1

- There is no effect of the filler particle hardness on the bending stiffness of a Vacu-SL shaft. $\left(\boldsymbol{H}_{0, \mathrm{~h}}\right)$

\section{Materials and methods}

It was decided to test the Vacu-SL shafts in an arced configuration and to load it in the direction that causes straightening of the bend. By doing this, the influence of foil stiffness is further reduced because the foil is straightened out in the inner curve of the bend and crumpled in the outer curve of the bend. Thereby, only the negligible bending stiffness, and not the considerable tensile strength of the foil, influences the bending stiffness of the Vacu-SL shaft. Another reason to use an arced configuration is that in practice, a Vacu-SL shaft will be used mostly to prevent the deformation of present bends in a flexible endoscope.

'Packing load' is the load used to compress the packing. Increasing packing load and packing density are known to increase the packing stability and thus to limit displacements of particles [18,19]. In a rigidified Vacu-SL shaft, the packing load is the pressure difference between the vacuum pressure inside the foil tube and the atmospheric pressure outside it and was set equal for all test models. The packing density depends on the packing load as well as on the method of filling the Vacu-SL shaft $[18,19]$.

\subsection{Filler particles}

Sixteen Vacu-SL test models were built and each filled with a distinct type of particles. The filler particles differed in size, shape or material. The filler particles were selected based on suitability for the application, and availability. In Table 1 all types of tested filler particles are listed, together with their available data and names. From now on, the particle names given in Table 1 are used whenever referring to particular filler particles. Figure 7 shows macro photographs of the filler particles.

Table 1 Properties and names of tested filler particles. Corundum particles consist of crystalline aluminum oxide, $\mathrm{Al}_{2} \mathrm{O}_{3}$

\begin{tabular}{llllll}
\hline Material (Shape) & Name & $\begin{array}{l}\text { Average } \\
\text { diameter [mm] }\end{array}$ & Size range [mm] & Supplier's product reference & Supplier (Country) \\
\hline Polystyrene (Sphere) & PL-S0.5 & 0.5 & & PS bolletjes & Hordijk (NL) \\
Acrylic Glass (Granulate) & AC-G0.3 & 0.3 & $0.25-0.36$ & Plasti-Grit Acrylic V 40/60 & Straaltechniek International (NL) \\
& AC-G0.5 & 0.5 & $0.36-0.60$ & Plasti-Grit Acrylic V 30/40 & Straaltechniek International (NL) \\
& AC-G0.7 & 0.7 & $0.60-0.85$ & Plasti-Grit Acrylic V 20/30 & Straaltechniek International (NL) \\
Glass (Sphere) & GL-S0.16 & 0.16 & $0.11-0.21$ & Glasparels & Eurogrit (NL) \\
& GL-S0.2 & 0.2 & $0.15-0.25$ & Glasparels & Eurogrit (NL) \\
& GL-S0.5 & 0.5 & $0.3-0.6$ & Glaspaerlen 400-800 $\mu$ & Swarco (GE) \\
(Pebble) & GL-S1.0 & 1.0 & $0.85-1.15$ & & Tokyu Hands (JP) \\
Steel (Sphere) & GL-P1.0 & 1.0 & $0.45-1.85$ & & Tokyu Hands (JP) \\
& ST-S0.2 & 0.2 & $0.1-0.3$ & Steelshots S070 & Eurogrit (NL) \\
& ST-S0.5 & 0.5 & $0.3-0.6$ & Steelshots S170 & Holland Mineraal (NL) \\
& ST-S0.6 & 0.6 & $0.5-0.7$ & Steelshots S230 & Eurogrit (NL) \\
ST-S1.0 & 1.0 & $0.84-1.19$ & Steelshots S330 & Eurogrit (NL) \\
Corundum (Ganulate) & AO-G1.0 & 1.0 & $0.7-1.2$ & Steelgrit G18 & Holland Mineraal (NL) \\
& AO-G1.7 & 1.7 & $0.85-1.7$ & Normaal Corund F.16 & Holland Mineraal (NL) \\
& & $1.2-2.3$ & Normaal Corund F.12 & Holland Mineraal (NL)
\end{tabular}


Different sizes within a group of particles that were obtained from different suppliers (e.g. within the steel spheres group) were confirmed to have similar hardness, chemical composition, and specific weight by using the supplier's data sheets. Similarly, particles of different shapes but equal material and size that were compared to one another were confirmed to be similar materials by using the supplier's data sheets.

\subsection{Preparations}

In order to minimize the influence of the filling method, all test models were filled identically: Each foil tube was first closed at one (the distal) end using the tip part and filled with particles for about $90 \%$ of its volume. Next, it was put in a mould (Fig. 3) in order to obtain the same bending radius for each test model. The two parts of the mould, with the partly closed tube in it, were merged with the open proximal end of the tube sticking out. The mould with the tube was placed on a vibrating plate. The tube was further filled with particles through a funnel, under constant vibration, in $60 \mathrm{~s}$.

After filling, the proximal end of the tube was closed with a hose connector that is connected to the hose of a vacuum pump. The vacuum pump (Type SV25, Leybold SA, France) was switched on, which almost instantly rigidified the test model. The rigidified test model was removed from the mould and placed in the test setup.

\subsection{Test conditions}

The vacuum pressure at the entrance of the hose connector was monitored during each measurement and varied between 0.6 and $2.0 \mathrm{kPa}$ but was constant during each individual measurement. Atmospheric pressure varied between 100.4 and $102.5 \mathrm{kPa}$. The resulting locking pressure for the VacuSL shaft (which is also the packing load for the filling) was $100.15 \mathrm{kPa}+/-1.7 \%$. All measurements were conducted at a lab temperature of $21.9+/-1.1^{\circ} \mathrm{C}$ and relative humidity of $46.7+/-4.3 \%$.

\subsection{Test setup}

The test setup is shown in Fig. 8. The rigidified test model is clamped in a holder, which is positioned such that the tip of the test model is perpendicular to the center line of the setup. Downwards bending of the test model, due to gravity, is prevented by suspending it with a $1 \mathrm{~m}$ long wire on the balancer. A pulling cord (Dyneema $(\mathbb{B}$ ) with a bending stiffness that is negligible with respect to the Vacu-SL test models) runs over a low friction pulley from the tip of the test model to the force sensor of a tensile tester. The average friction force introduced by the pulley was measured to be variable but less than $2 \mathrm{mN}$ over the entire range of measurements and thus

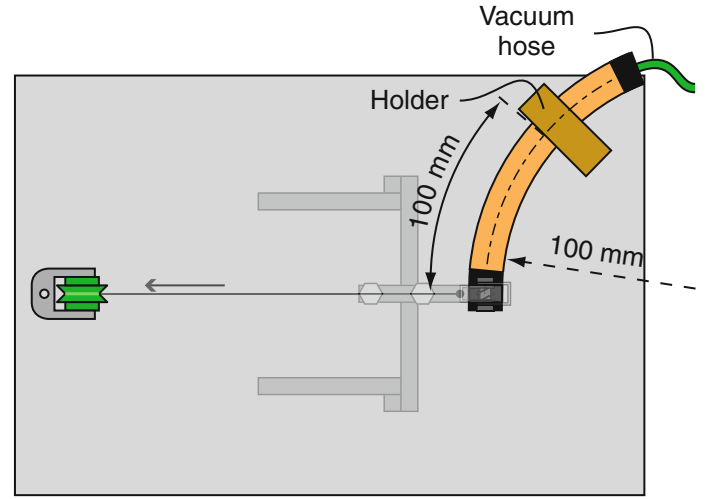

(Top view)

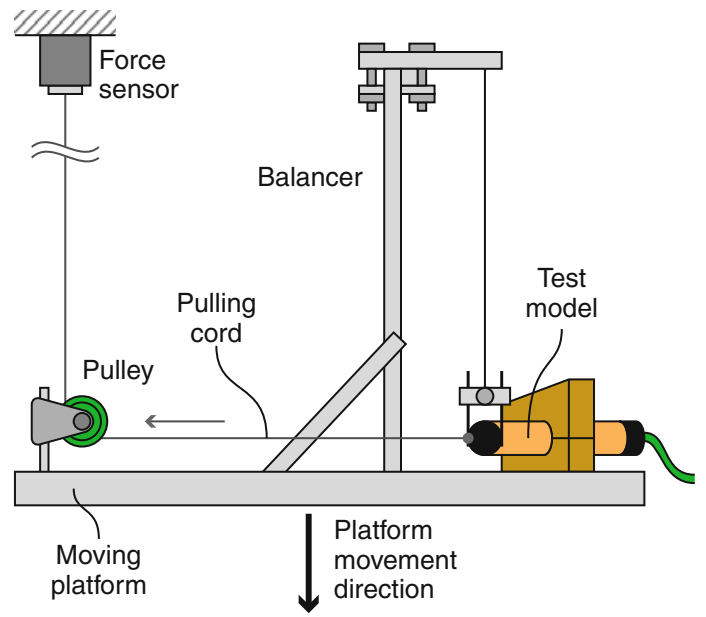

(Side view)

Fig. 8 Top and side view of the setup used to test Vacu-SL test models. The test model is rigidified and connected to a force sensor, which measures the pulling force in the pulling cord (which is the deflection force on the test model tip) when the platform moves down. The platform displacement is recorded together with the force data

negligible. The pulling cord had to be tensioned during the start of each measurement since the cord was kept slightly longer than necessary in order to enable easy working during the tests. The tensioning is shown in the upper part of Fig. 9 where the force stays at a very low value up to $20-25 \mathrm{~mm}$ displacement. This startup behavior was removed by applying a $20 \mathrm{mN}$ threshold to the data.

The holder, balancer and pulley, are all fixed on the moving platform of a tensile tester (Zwick Type 1484, Zwick GmbH \& Co., Germany). When the platform moves downwards with respect to the force sensor, the test model is deformed by a deflection force, which is the pulling force that is exerted by the tensile testing machine. The pulling force and the displacement of the platform were recorded.

During pilot tests, it appeared that the elasticity of the pulling cord strongly influenced the results, even though the pulling force did not rise above $3 \mathrm{~N}$. Therefore, a series of tests was carried out in order to quantify the 

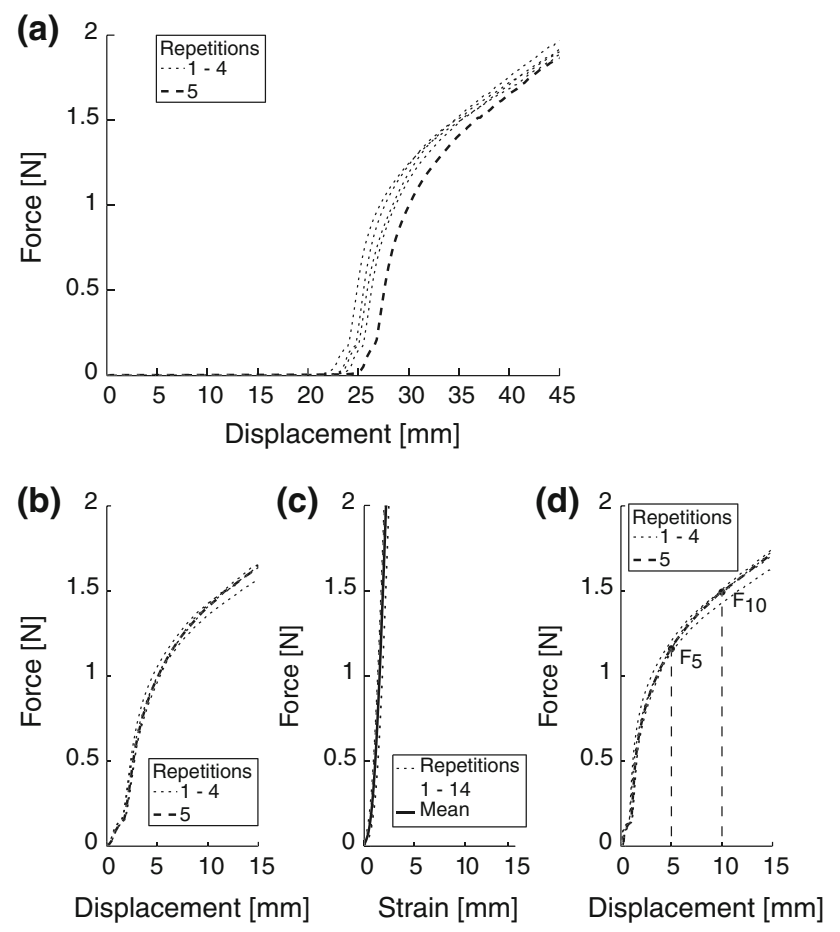

Fig. 9 Explanation of data preparation. First a $20 \mathrm{mN}$ cutoff is applied to the raw data in order to remove the effects of friction in the setup and align the data. Next, the force-strain behavior of the Dyneema pulling cord is measured. At each force level, the displacement of the test model tip is corrected by subtracting the corresponding strain in the pulling cord. From the corrected data, the deflection forces at 5 and $10 \mathrm{~mm}$ are taken for comparison of the Vacu-SL filler types

influence of the pulling cord. The pulling cord was attached to a screw on the moving platform. Next, a tensile test up to $3 \mathrm{~N}$ was carried out with fourteen repetitions. The results thereof are given in Fig. 9. In order to obtain the true forcedisplacement characteristics of the test models, the mean of the pulling cord's force-displacement characteristics was smoothed with a moving average and subtracted from the raw results of the measurements on the test models.

\subsection{Between measurements}

Before each measurement the test model was put back in its initial curved state. It was made compliant by relieving the vacuum, and put vertically on a vibrating plate. By vibrating the test model for $10 \mathrm{~s}$, the particles packed to a stable minimum volume and rearrangements caused by previous deformations were removed. Finally, the test model was put in the mould again and vibrated to obtain the proper shape and be rigidified for the measurement.

\subsection{Statistics}

After subtracting the force-displacement effects of the Dyneema rope tensioning, the deflection forces needed to deflect each rigidified Vacu-SL shaft 5 and $10 \mathrm{~mm}$ in the pulling direction $\left(\mathrm{F}_{5}\right.$ and $\mathrm{F}_{10}$ respectively) were determined (Fig. 9, bottom right). The measured values for $\mathrm{F}_{5}$ and $\mathrm{F}_{10}$ for the different filler particles were analyzed using one-way ANOVA tests in Matlab (version 2007b) for each hypothesis (size, shape and hardness). Differences were regarded significant when $p<0.05$.

There was no obvious need to randomize the order of the measurements. All measurements were independent and atmospheric variations in our lab were negligible. All measurements were performed whenever convenient for practical reasons.

\section{Results}

The results of the measurements are given as notched box plots in Figs. 10, 11, 12, showing the $F_{5}$ and $F_{10}$ values for different sizes, shapes and elasticity respectively. The vertical lines in the plots group the filler types that were compared to one another. The groups where chosen such that particles within a group differ (as good as possible) by only one of the three properties of interest.

The white filled and grey filled boxes are the $F_{5}$ and $F_{10}$ data, respectively. The notches in the boxes indicate the $95 \%$ confidence interval for the true medians. If the notches of two boxes do not overlap, there is strong proof that their true medians are different.

\subsection{Size}

There is no significant difference between Vacu-SL shafts filled with $1.0 \mathrm{~mm}$ or $1.7 \mathrm{~mm}$ granules of corundum (Fig. 10). However, for acrylic glass granules, glass spheres and steel spheres the results differ significantly for different sizes, falsifying hypothesis $\mathrm{H}_{0, \mathrm{~s}}$. For these materials only particle sizes of $1.0 \mathrm{~mm}$ and smaller were tested.

For acrylic glass granules, the deflection force is higher for smaller particles, in the range of $0.3-0.7 \mathrm{~mm}$. For glass and steel spheres, the deflection force is higher for smaller particles but not with a linear relationship. The deflection force is lower for glass spheres of $0.16 \mathrm{~mm}$ than for glass spheres of $0.2 \mathrm{~mm}$, while the $0.2 \mathrm{~mm}$ spheres perform better than the larger ones. This suggests an optimal particle size between 0.16 and $1.0 \mathrm{~mm}$ for glass spheres.

For steel spheres, a similar situation is seen, but with smaller differences. For steel spheres from 0.2 to $0.6 \mathrm{~mm}$ increasing size seems to increase the deflection force although the results are not significantly different. The deflection force for steel spheres of $1.0 \mathrm{~mm}$ is significantly lower than for $0.6 \mathrm{~mm}$, which suggests an optimal size somewhere between 0.5 and $1.0 \mathrm{~mm}$. 


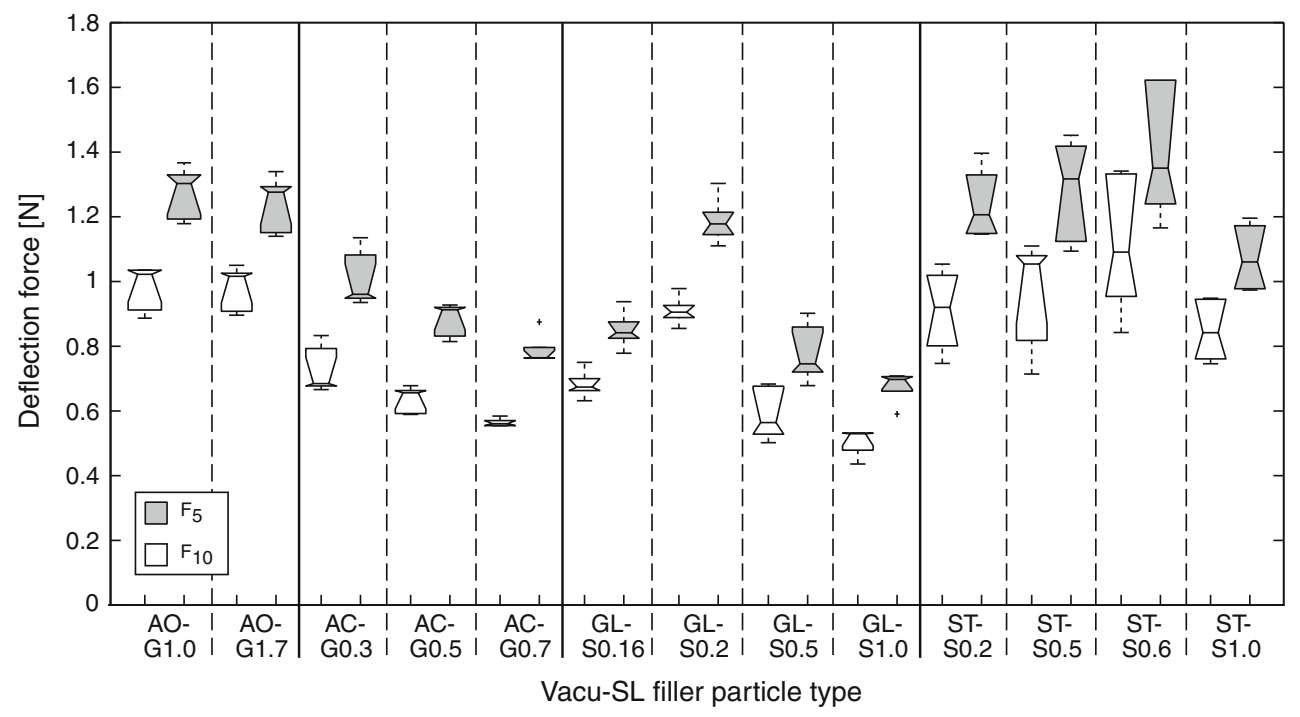

Fig. 10 Influence of filler particle size on deflection forces $F_{5}$ and $F_{10}$ (for 5 and $10 \mathrm{~mm}$ deflection respectively) of a rigidified Vacu-SL test model. Particles were compared within their own group only. Groups are separated with thick vertical black lines. The results are presented as notched box and whisker plots. The top, middle and bottom line of each box represent the upper quartile, median and lower quartile. The

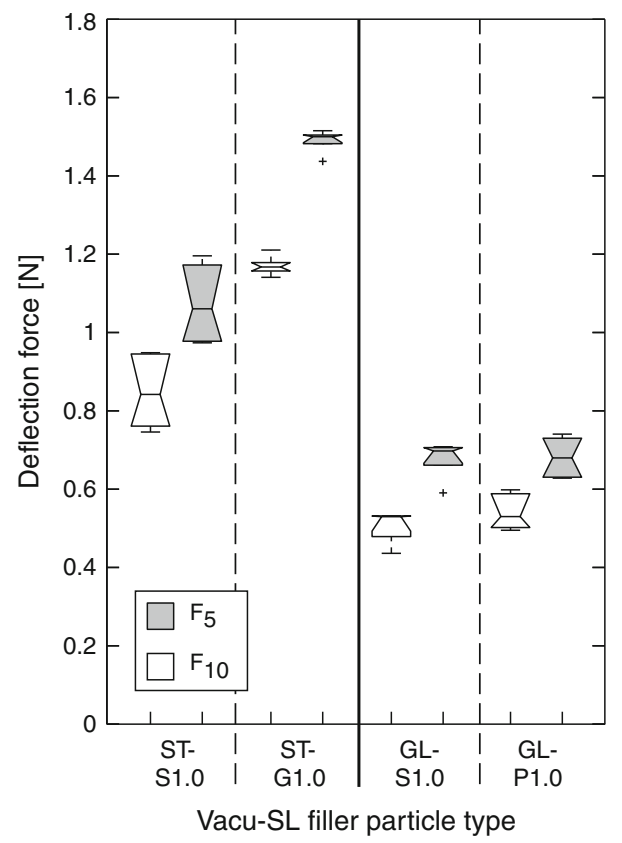

Fig. 11 Influence of filler particle shape on deflection forces $\mathrm{F}_{5}$ and $\mathrm{F}_{10}$ (for 5 and $10 \mathrm{~mm}$ deflection respectively) of a rigidified Vacu-SL test model. The data is presented similarly as in Fig. 10. Filler particle types' properties are listed in Table 1 and shown in Fig. 7

\subsection{Shape}

The glass pebbles and glass spheres show no significant difference. However, there is a significant difference between whiskers, extending from the ends of the boxes, represent the range within which the rest of the data falls. Outliers are represented by a ' + '. The notches represent the $95 \%$ confidence interval for the true median. If the notches of two boxes do not overlap, there is strong evidence that their true medians are significantly different $(p<0.05)$. Filler particle types' properties are listed in Table 1 and shown in Fig. 7

steel granules and steel spheres (Fig. 11). This indicates a shape effect for large shape differences, falsifying hypothesis $\mathrm{H}_{0, \mathrm{v}}$.

\subsection{Hardness}

Steel granules perform significantly better than the harder corundum granules, and steel spheres perform significantly better than the harder glass and softer polystyrene spheres (Fig. 12). These results show a hardness effect, falsifying hypothesis $\mathrm{H}_{0, \mathrm{~h}}$, but suggest that there is an optimal hardness.

\section{Discussion}

\subsection{Size}

The results on size effects (Fig. 10) partly agree with our expectations. The granules show no difference for different sizes. The acrylic glass spheres show increasing deflection forces for decreasing particles size. The same goes for the glass and steel spheres up to certain, possibly optimal, sizes. Apparently, there is some influence of particle size that increases the bending stiffness of a Vacu-SL shaft with decreasing particle size. This could be caused by a relation between the foil tube diameter and the particle size, and the distribution of the particles inside the foil tube. As discussed in the 'Theory and Literature' section this agrees with 


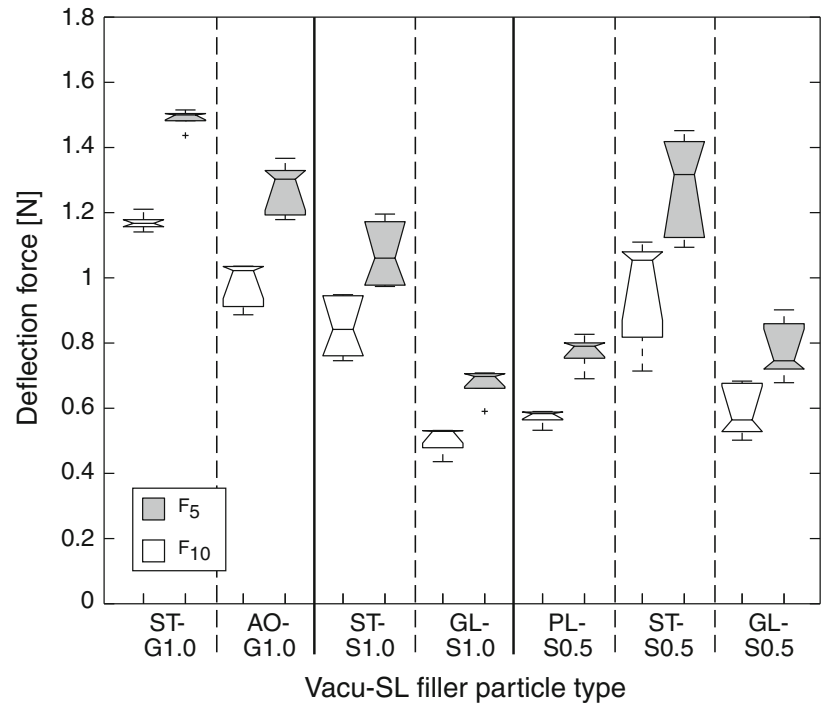

Fig. 12 Influence of filler particle hardness on deflection forces $\mathrm{F}_{5}$ and $\mathrm{F}_{10}$ (for 5 and $10 \mathrm{~mm}$ deflection respectively) of a rigidified Vacu-SL test model. The data is presented similarly as in Fig. 10. Filler particle types' properties are listed in Table 1 and shown in Fig. 7

measurements on the angle of stability of piled layers of particles, done by Aguirre et al. [25,26]. They showed that the angles of stability and repose increase with packing density and with the number of layers of particles. Blair et al. [27] showed that the probability density of forces in the packing depends on the number of layers as well, implicating that a more beneficial force distribution might be formed by using more layers, i.e. smaller particles in the Vacu-SL shaft.

Due to the lack of space for proper packing in the case of relatively large particles in a Vacu-SL shaft, many large voids can occur due to boundary effects in the packing and increased mobility of particles in the boundary layers [17]. Figure 13 shows the limit case of what happens when spherical particles are large compared to the foil tube diameter. The particles are no longer enclosed from multiple sides and can even act as rolling joints, weakening the Vacu-SL shaft. In Fig. 2 the particles are very small compared to the foil tube diameter. In order to deform this volume of particles, a large number of fully enclosed particles must change position.

Reducing the sizes of the glass spheres too much causes a marked reduction of the Vacu-SL shaft bending stiffness. We suspected that this is partly caused by the fact that when the particles become smaller, the voids between the particles become smaller and the particles can get in the pores of the cotton cloth membrane. These effects might block the airflow and thereby prevent a proper vacuum pressure in the distal part of the Vacu-SL shaft in the relatively short time that was used to rigidify the test models. However, the size below which the performance deteriorates, is different for glass and steel spheres. If the theory about blocked airflow

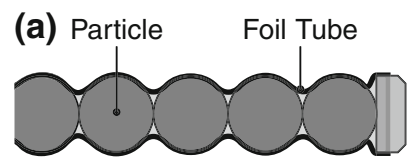

(b)

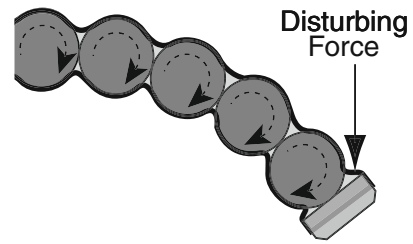

Fig. 13 Possible reason why large particles reduce the Vacu-SL stiffness. a Limit case for particle size. Filler particle size equals foil tube inner diameter. b Due to the large particle size, the particles cannot form a stable packing. In the limit case, the particles even form rolling links and will readily give way to an external force (vertical arrow) by rotating

would be true, the particle size at which this occurs should be equal for all material types since it is only a geometrical relation.

In order to check if airflow blocking occurred, the GL-S0.16 and GL-S0.2 test models were rigidified five times while the pressure at the distal end was measured. Surprisingly, the distal inside pressure was $18.5 \mathrm{kPa}$ for GL-S0.16 and $35.0 \mathrm{kPa}$ for GL-S0.2, whereas GL-S0.2 performed much better in the tests (Fig. 10). Apparently, blocking of the air flow by too small particles is not what caused the reduced bending stiffness for the GL-S0.16 particles.

Although the surface finish, specific density and hardness values were identical to other glass particles, the GL-S0.5 particles did have a chemical composition that differed slightly from the other glass particles. The GL-S0.5 data sheet indicated a silicon oxide content of at least $65 \%$ whereas the datasheets indicated $72-73 \%$ for the other particles. However, since hardness and density were identical for all glass particles and since these properties are coupled to other material properties, it is not expected that there is a significant difference in friction or elasticity. Therefore, it is unlikely that the slightly differing chemical composition the performance reduction of GL-S0.5.

The absolute range of particle sizes within the different filler types (polydispersity) is not always equal. For example, the ST-S0.5 particles have sizes varying within a $0.2 \mathrm{~mm}$ range while the ST-S1.0 particles vary within a $0.35 \mathrm{~mm}$ range. The same goes for the glass spheres, where the larger size also has a larger absolute polydispersity. Luding's static two-dimensional, frictionless, granular media model indicated that even small changes in the absolute polydispersity have a significant effect on the contact network and stress distributions in a pile of spheres [29]. This might partly explain the large deflection force differences between 0.6 and $1 \mathrm{~mm}$ steel spheres and between 0.2 and $1.0 \mathrm{~mm}$ glass spheres. 
However, details about the weakening or strengthening effects of increasing polydispersity are yet unknown.

\subsection{Shape}

The results on glass spheres and glass pebbles (Fig. 11) agree with the simulations of Kuhn and Bagi, which showed little difference between the amount of particle rotations for spherical and ovoid particles [24]. The shape difference is much larger between the steel granules and spheres than between the glass spheres and pebbles (Fig. 7). For the tested steel particles hypothesis $\mathrm{H}_{0, \mathrm{v}}$ is falsified (Fig. 11), indicating that the shape of the filler particles affects the bending stiffness of a Vacu-SL shaft and that edgy particles provide higher bending stiffness than rounded ones. This agrees with literature as discussed above [19-23].

\subsection{Hardness}

Steel performs significantly better than the harder corundum and the harder glass but also better than the softer polystyrene particles (Fig. 12). This agrees with the theories about hardness effects discussed above. The filler particles must be hard enough to limit indentation or compression of the particles, though soft enough to enable the formation of more profitable contact points that prevent particle rolling. The same is valid for particles that are already irregularly shaped, as shown by the difference between steel and corundum granules.

However, a quick calculation, based on Hertzian contacts and simple beam theory, for the steel and polystyrene spheres of $0.5 \mathrm{~mm}$ diameter in the most compressed outer layers of the Vacu-SL shaft, indicated that even at the maximum measured values of $F_{10}$, the total shaft compression due to particle indentation is only of the order of $0.01 \mathrm{~mm}[30,31]$. The particle indentation at the contact points does not exceed 0.62 $\mu \mathrm{m}$. We did not consider increased particle loading due to the formation of high-load carrying chains. However, it is unlikely that this would increase maximum particle loading with more than a factor of 5 , considering the usual probability distributions of normal forces between particles [27,32]. At first sight, there seems to be insufficient particle deformation to improve the packing due to particle shape changes.

An inconvenient consequence of comparing particles of different elasticity is that also the frictional properties of the particle materials might differ. It might be useful to investigate to what extent friction determines the measured variations. This could be done by using lubrication to disable the friction between the particles. However, lubrication can increase friction due to capillary forces [33], give various results for different sizes and shapes of particles [22], and might fail to disable the self mated friction of the particles due to the presence of boundary lubrication [34].
Another method to influence friction is adaptation of surface roughness. However, since the self-mated friction of corundum, steel and glass follows Coulomb's laws for broad ranges of roughness, the friction coefficients of these particles might not change notably by changing the surface roughness of the grains [34]. Furthermore, when using volumes of a single type of particles, the particles most likely all have the same roughness. Porgess et al. showed that in such contact situations of equal material and roughness the friction is at a minimum value that is independent of the roughness value and nearly constant for many different materials [35]. The glass particles however, were very smooth (likely outside the range of roughness independence) and could be treated to reduce the self-mated friction by etching, as was done by Blair et al. who showed no effect of particle friction on the force distribution in granular packings of spheres [27].

Clearly, although it is valuable to study the role of particle friction on the performance of a Vacu-SL shaft, controlling this variable might be quite complicated. However, typical self-mated static friction coefficients in air are 0.7 for corundum [36], 0.6-0.8 for steel [34], 0.9 for glass [34] and 0.5 for polystyrene [34]. Since the friction of the corundum and steel granules is comparable it is assumed to have had no significant influence on our results. According to Oda et al., if friction is too high to enable sliding of rounded particles, the movements of the particles change into rolling, causing friction to have little effect on the overall stiffness of a volume of rounded particles [21]. Therefore the effect of friction on the bending stiffness of a Vacu-SL shaft is assumed to have had only minor influence on the results for spherical particles. This does not imply that the role of friction should not be studied further. In fact, increasing friction between particles will likely be a viable method to increase the performance of Vacu-SL shafts filled with granules and the effect of friction will be investigated in later experiments.

Apparently granules also attain a more stable configuration when even a small amount of particle deformation is possible. The results indicate that filler particle hardness affects the bending stiffness of a Vacu-SL shaft. However, although the results suggest that there is an optimal value for the particle hardness, it is not yet clear how this optimum can be calculated because all of the above treated filler volume deformation mechanisms depend on it to some extent. In order to calculate the optimal particle hardness, more knowledge is required about the deformation of a closed and loaded volume of granular media under uniform pressure.

\subsection{Limitations and implications}

The possible dependence of the vacuum pressure in the distal part of the Vacu-SL shaft on the type of filler particles can be overcome by applying pressure from the outside of the Vacu-SL shaft. That way, the applied locking pressure is 
uncoupled from the contents of the Vacu-SL shaft. However, this will also add more parts to the design, making it more complex. Another possibility would be to put a central tube, with membrane covered holes along its length, in the center of the Vacu-SL shaft. When using this tube for suction, the proper pressure will be obtained faster and better controlled throughout the entire shaft, which is especially useful for longer shafts.

When watching Fig. 7 carefully one can discover small impurities between the filler particles in some cases. These impurities can be small particles of another material or particles having a slightly different shape than the main volume of particles. Such impurities influence the bending stiffness of a Vacu-SL shaft by filling voids or blocking movement of other filler particles. However, the effects of the scarce amount of impurities and differently shaped particles are assumed to be negligible. This is also suggested by the small effect of the shape difference between glass spheres and glass pebbles in our measurements and in literature [24].

For maximum bending stiffness of a Vacu-SL shaft, steel granules seem to be the filler particles of choice. A clear size effect for acrylic glass granules and for steel spheres was shown. Therefore, further improvement is expected by using steel granules smaller than $1.0 \mathrm{~mm}$. It should be kept in mind though, that there might be a minimum particle size below which the performance drastically drops again. A drawback of steel granules is their weight. A full length Vacu-SL endoscope filled with steel particles will be about seven times heavier than one filled with acrylic glass particles. However, acrylic glass granules provide only two thirds of the bending stiffness that corresponding steel spheres can provide.

The next question is of course; what bending stiffness is required? Wehrmeier et al. measured the flexural rigidity (product of the endoscope shaft's Young's modulus and the moment of inertia of its cross-section) of several flexible endoscopes for the colon to be $165-220 \mathrm{Ncm}^{2}$. [37] When using the basic formula (in this case over simplified since there is a large deflection) for the deflection of a simple beam under a single load at its tip, one can calculate that a force of $2.5 \mathrm{~N}$ is needed to force to bend and keep an endoscope with 165 $\mathrm{Ncm}^{2}$ flexural rigidity in roughly the same configuration as the Vacu-SL shaft in Fig. 3 [38]. This force is significantly larger than $\mathrm{F}_{10}$ for ST-G1.0 $(1.5 \mathrm{~N})$, which was the largest measured deflection force. Furthermore, a Vacu-SL shaft has zero strain in any configuration that it is rigidified in. Therefore, it will be even less capable of constraining the endoscope shaft (whose resisting force increases with further bending) in configurations with sharper bends than the one in Fig. 3.

In order to use a Vacu-SL shaft with a flexible endoscope, it should either have a vacant center in which a flexible endoscope or its essential parts fit, or be small enough to fit in a flexible endoscope. Both variants will reduce the
Vacu-SL shaft's flexural rigidity unless its diameter is increased, which is not preferred and only allowed to a certain extent due to human anatomical limitations (maximally $25 \mathrm{~mm}$ for anal insertion).

In practice, an endoscope must often be bent sharper than the Vacu-SL test model in Fig. 3 and will thus exert a larger force than $2.5 \mathrm{~N}$ on the Vacu-SL shaft, although hysteresis of the endoscope shaft will decrease the force needed to keep the endoscope shaft in the required shape once it is bent. Furthermore, during tissue manipulations additive forces are exerted on the Vacu-SL shaft. Therefore the suitability of the tested Vacu-SL filler particle types for the support of regular flexible endoscopes is limited, especially when applied in smaller diameters.

Ways should be found to further increase the performance of the Vacu-SL mechanism. The results of this study suggest that more stiffness will be obtained by using granules smaller than $1.0 \mathrm{~mm}$. Furthermore, it is useful to test the performance of mixed volumes of filler particles in Vacu-SL shafts. The results of the current study suggest that a mixture of very hard particles and smaller, softer particles could further improve the bending stiffness of a Vacu-SL shaft. This agrees with literature on reinforcing soils by granular mixing and lightweight fillers [26,39-41]. The large, hard particles prevent deformation that is caused by compression of the particles. The small, soft particles (if small enough and well mixed) can be compressed, compact the packing by matching and filling voids, and prevent load carrying chains of hard particles from buckling.

\section{Conclusion}

The Vacu-SL mechanism seems to be a reliable and simple mechanism to control the bending stiffness of a flexible shaft. The bending stiffness that can be obtained in the rigidified state of a Vacu-SL shaft depends largely on the filler particles that are used. The results of the current study show that particle size, shape and elasticity can all be applied to improve the bending stiffness of a rigidified Vacu-SL shaft. Generally, smaller particles gave a higher bending stiffness than larger particles to some extent but the results also suggested an optimal particle size below which the bending stiffness dropped again. Granules gave a higher bending stiffness than spheres. Steel particles gave a higher bending stiffness than corundum particles but also higher than glass or polystyrene particles. The latter is likely to be explained by particle deformations causing a part of the Vacu-SL shaft deformation but at the same time preventing other deformation types by allowing more stable packing of the particles. Particle friction should not be excluded as a factor influencing the Vacu-SL performance. Although the Vacu-SL mechanism is simple and reliable, the largest deflection force at $10 \mathrm{~mm}$ deflection was 
$1.5 \mathrm{~N}$, which at this moment does not seem to be enough to properly guide or rigidify a regular flexible endoscope. However, the results also indicate that there are several ways to improve the concept by changing the Vacu-SL filler particles.

Acknowledgments These tests were made possible due to Marc Los' efforts in the pilot studies and the efforts of Sebastiaan Kiemel and Martijn Jansen during the tests. Marc, Sebastiaan and Martijn are Mechanical Engineering students of the Delft University of Technology.

Open Access This article is distributed under the terms of the Creative Commons Attribution Noncommercial License which permits any noncommercial use, distribution, and reproduction in any medium, provided the original author(s) and source are credited.

\section{References}

1. Baillie, J.: The endoscope. Gastrointest. Endosc. 65, 886893 (2007)

2. Hawes, R.H., Rattner, D.W., Fleischer, D., et al.: NOTES(TM): where have we been and where are we going?. Gastrointest. Endosc. 67, 779-780 (2008)

3. Rattner, D., Kalloo, A.: ASGE/SAGES Working Group on Natural Orifice Translumenal Endoscopic Surgery: October 2005. Surg. Endosc. 20, 329-333 (2006)

4. Shih, S.P., Kantsevoy, S.V., Kalloo, A.N., et al.: Hybrid minimally invasive surgery - A bridge between laparoscopic and translumenal surgery. Surg. Endosc. 21, 1450-1453 (2007)

5. Swain, P.: A justification for NOTES-natural orifice translumenal endosurgery. Gastrointest. Endosc. 65, 514-516 (2007)

6. Church, J., Delaney, C.: Randomized, Controlled Trial of Carbon Dioxide Insufflation During Colonoscopy. Dis. Colon Rectum 46, 322-326 (2003)

7. Church, J.M.: Ancillary colonoscope insertion techniques-an evaluation. Surg. Endosc. 7, 191-193 (1993)

8. Hull, T., Church, J.M.: Colonoscopy-how difficult, how painful?. Surg. Endosc. 8, 784-787 (1994)

9. Lee, S.H., Chung, I.K., Kim, S.J., et al.: An adequate level of training for technical competence in screening and diagnostic colonoscopy: a prospective multicenter evaluation of the learning curve. Gastrointest. Endosc. 67, 7 (2008)

10. Leung, F.W.: Methods of reducing discomfort during colonoscopy. Dig. Dis. Sci. 53(6), 1-6 (2008)

11. Shah, S.G., Saunders, B.P., Brooker, J.C., et al.: Magnetic imaging of colonoscopy: an audit of looping, accuracy and ancillary maneuvers. Gastrointest. Endosc. 52, 1-8 (2000)

12. Waye, J.D., Rex, D.K., Williams, C.B.: Colonoscopy: Principles and Practice. Blackwell Pub, Oxford (2003)

13. Campanaro, L., Goldstone, N.J., Shepherd, C.C.: Rigidized evacuated structure. US Patent 3,258,883, July 5 (1966)

14. Loeb, J., Plantif, B.E.P.J.: Systeme de protection par modelage sous forme d'enceinte deformable et rigidifiable par depression, (FR). CA Patent (Brevet Canadien) 1035055, July 18 (1978)

15. Rose, F.L.: Vacuum formed support structures and immobilizer devices. Bio-Medical Systems, Inc., Danbury, CT, US Patent 3,745,998, July 17 (1973)

16. Zinner, N.R., Sterling A.M.: Penile prosthesis and method. Torracne, CA, US Patent 5,069,201, December 3 (1991)

17. Reynolds, O.: On the dilatancy of media composed of rigid particles in contact. Philos. Magazine 20, 469-481 (1885)

18. Revuzhenko, A.F., Filippovich, A.: Mechanics of granular media. Springer, Berlin (2006)
19. Olson, J., Priester, M., Luo, J., et al.: Packing fractions and maximum angles of stability of granular materials. Phys. Rev. E 72, 031302 (2005)

20. Guises, R., Xiang, J., Latham, J.P., et al.: Granular packing: numerical simulation and the characterisation of the effect of particle shape. Granul. Matter 11, 281-292 (2009)

21. Oda, M., Konishi, J., Nemat-Nasser, S.: Experimental micromechanical evaluation of strength of granular materials: effects of particle rolling. Mech. Mater. 1, 269-283 (1982)

22. Podczeck, F., Miah, Y.: The influence of particle size and shape on the angle of internal friction and the flow factor of unlubricated and lubricated powders. Int. J. Pharm. 144, 187-194 (1996)

23. Ludewig, F., Vandewalle, N., Dorbolo, S.: Compaction of granular mixtures. Granul. Matter 8, 87-91 (2006)

24. Kuhn, M.R., Bagi, K.: Contact rolling and deformation in granular media. Int. J. Solids. Struct. 41, 5793-5820 (2004)

25. Aguirre, M.A., Nerone, N., Calvo, A., et al.: Influence of the number of layers on the equilibrium of a granular packing. Physical Review E - Statistical Physics, Plasmas, Fluids, and Related Interdisciplinary Topics 62, 738-743 (2000)

26. Aguirre, M.A., Nerone, N., Ippolito, I., et al.: Granular packing: influence of different parameters on its stability. Granul. Matter 3, 75-77 (2001)

27. Blair, D.L., Mueggenburg, N.W., Marshall, A.H., et al.: Force distributions in three-dimensional granular assemblies: effects of packing order and interparticle friction. Physical Review E - Statistical, Nonlinear, and Soft Matter Physics 63, 413041413048 (2001)

28. Kadau, D., Schwesig, D., Theuerkauf, J., et al.: Influence of particle elasticity in shear testers. Granul. Matter 8, 35-40 (2006)

29. Luding, S.: Stress distribution in static two-dimensional granular model media in the absence of friction. Phys. Rev. E 55, 4720 4729 (1997)

30. Dintwa, E., Tijskens, E., Ramon, H.: On the accuracy of the Hertz model to describe the normal contact of soft elastic spheres. Granul. Matter 10, 209-221 (2008)

31. van Beek, A.: Advanced engineering design: lifetime performance and reliability. Delft University of Technology, Mechanical Engineering, Delft, The Netherlands (2006)

32. Radjai, F., Wolf, D.E.: Features of static pressure in dense granular media. Granul. Matter 1, 3-8 (1998)

33. Soria-Hoyo, C., Valverde, J.M., Castellanos, A.: Avalanches in moistened beds of glass beads. Powder Technol. 196, 257262 (2009)

34. Bowden, F.P., Tabor, D.: The friction and lubrication of solids. Oxford University Press, Oxford (1950)

35. Porgess, P.V.K., Wilman, H.: The dependence of friction on surface roughness. Proc. Royal Soc. Lond. Series A Math. Phy. Sci. 252, 35-44 (1959)

36. Bhushan, B.: Modern Tribology Handbook. CRC Press LLC, Boca Raton (2001)

37. Wehrmeyer, J.A., Barthel, J.A., Roth, J.P., et al.: Colonoscope flexural rigidity measurement. Med. Biol. Eng. Comput 36, 475479 (1998)

38. Gere, J.M., Timoshenko, S.P.: Mechanics of materials. Stanley Thornes (Publishers) Ltd, Cheltenham, UK (1999)

39. Ghazavi, M.: Shear strength characteristics of sand-mixed with granular rubber. Geotech. Geol. Eng. 22, 401-416 (2004)

40. Kim, H.K., Santamarina, J.C.: Sand-rubber mixtures (large rubber chips). Can. Geotech. J. 45, 1457-1466 (2008)

41. Lee, J.S., Dodds, J., Santamarina, J.C.: Behavior of rigid-soft particle mixtures. J. Mater. Civ. Eng. 19, 179-184 (2007) 